This item was submitted to Loughborough's Research Repository by the author.

Items in Figshare are protected by copyright, with all rights reserved, unless otherwise indicated.

\title{
Muscle tension increases impact force but decreases energy absorption and pain during visco-elastic impacts to human thighs
}

PLEASE CITE THE PUBLISHED VERSION

https://doi.org/10.1016/j.jbiomech.2017.11.032

\section{PUBLISHER}

(C) Elsevier

\section{VERSION}

AM (Accepted Manuscript)

\section{PUBLISHER STATEMENT}

This work is made available according to the conditions of the Creative Commons Attribution-NonCommercialNoDerivatives 4.0 International (CC BY-NC-ND 4.0) licence. Full details of this licence are available at: https://creativecommons.org/licenses/by-nc-nd/4.0/

\section{LICENCE}

CC BY-NC-ND 4.0

\section{REPOSITORY RECORD}

Tsui, Felix, and Matthew Pain. 2017. "Muscle Tension Increases Impact Force but Decreases Energy Absorption and Pain During Visco-elastic Impacts to Human Thighs". Loughborough University. https://hdl.handle.net/2134/27940. 
Muscle tension increases impact force but decreases energy absorption and pain during visco-elastic impacts to human thighs

Felix Tsui ${ }^{1}$ and Matthew T.G. Pain ${ }^{2}$

${ }^{1}$ Vicon Denver, 7388 S. Revere Parkway Suite 901 Centennial, CO 80112, USA

${ }^{2}$ School of Sport, Exercise and Health Sciences, Loughborough University, LE11 3TU, UK.

Corresponding author:

Matthew TG Pain

School of Sport, Exercise and Health Sciences

Loughborough University

Loughborough LE11 3TU

UK

Email: m.t.g.pain@lboro.ac.uk

Tel. no: +44 (0)1509 226327 


\section{Abstract}

Despite uncertainty of its exact role, muscle tension has shown an ability to alter human biomechanical response and may have the ability to reduce impact injury severity. The aim of this study was to examine the effects of muscle tension on human impact response in terms of force and energy absorbed and the subjects' perceptions of pain. Seven male martial artists had a $3.9 \mathrm{~kg}$ medicine ball dropped vertically from seven different heights, 1.0-1.6 $\mathrm{m}$ in equal increments, onto their right thigh. Subjects were instructed to either relax or tense the quadriceps via knee extension ( $\geq 60 \% \mathrm{MVC}$ ) prior to each impact. Fscan pressure insoles sampling at $500 \mathrm{~Hz}$ recorded impact force and video was recorded at $1000 \mathrm{~Hz}$ to determine energy loss from the medicine ball during impact. Across all impacts force was $11 \%$ higher, energy absorption was $15 \%$ lower and time to peak force was $11 \%$ lower whilst perceived impact intensity was significantly lower when tensed. Whether muscle is tensed or not had a significant and meaningful effect on perceived discomfort. However, it did not relate to impact force between tensed conditions and so tensing may alter localised injury risk during human on human type impacts.

Keywords: discomfort; injury risk; collision; muscle activation 


\section{Introduction}

In sport, during crashes and accidental collisions if there is forewarning it is the norm to 'tense up' to receive an impact, and this is beneficial at the whole body level. Within sports with impacts players tense up both to deliver and receive impacts, and do so differently in varying conditions (Cazzola et al. 2015; Seminati et al. 2016), as well as specifically training and pre-activating muscle groups to reduce impulsive head loading (Eckner et al. 2014). Tensing muscle can reduce limb and torso acceleration and displacement (Muggenthaler et al. 2008), reduce whiplash (Bauer et al. 2001; Brolin et al. 2005), and reduce chest compression (Kemper et al. 2014). Research into the effects of muscle tension on injury risk has been primarily on thoracic stiffness during in vivo crash test studies. Early work found thoracic stiffness increases of $121-337 \%$ between tensed and relaxed human volunteers (Lobdell et al. 1973; Stalnaker et al. 1973; Patrick et al. 1981; Backaitis \& St. Laurent 1986). However, Kent et al. $(2003,2006)$ suggested that muscle tension was an unnecessary consideration for crash injury analysis as it made a negligible difference in thoracic stiffness above the injury compression threshold for irreversible injury.

With the development of whole body models for crash test simulations, both finite element models and multibody models (e.g. THUMS, HUMOS, MADYMO), and the development of more biofidelic testing methods for personal protective equipment (Pain et al. 2008; Hrysomallis 2009; Payne et al. 2016), the effects of muscle tension on impact response needs better quantification. Tensing muscle has been found to change the kinetics of impacts without altering the gross kinematics due to soft tissue intra-segmental motion. Increased muscle tension led to decreased intersegmental tissue movement, increased peak force, decreased time to peak force (Pain \& Challis 2001, 2002, 2004, 2006) and soft tissues were found to account for up to $70 \%$ of energy dissipated (Pain \& Challis 2002). Given the ubiquity of tensing musculature for an impact in sport it is surprising there is almost no literature examining effects of muscle tension on localised response to an impact, and whether, or how, it can reduce the risk of localised injuries.

Skeletal muscle contusions are one of the most common muscle injuries (Whiting and Zernicke 2008; de Souza \& Gottfried 2013). In their review 'Muscle Injury: Review of experimental models' de Souza and Gottfried (2013) described the crush model and the more common, and ecologically valid, blunt non-penetrating impacts model, invariably 
performed on animals. Crisco et al. (1996) performed blunt impacts with a solid nylon impactor onto the gastrocnemius of rats whilst the muscle was tensed for one limb and relaxed for the other. They had hypothesised that impact severity and severity of contusion would be greater in the tensed state but found the peak force decreased and less energy was absorbed during the impact when the muscle was tensed. They ascribed this reversal of their hypothesis to the tensed muscle stopping the impact being dominated by the bone of the limb, with the stiffer muscle reducing the compression of the muscle tissue between the impactor and the bone.

Very few equivalent impactor studies on humans have been carried out even at lower relative impact energies. In the PhD of Hyrsomallis (1996) impacts to the relaxed and tensed thigh of human volunteers were reported, but in a published paper of this work, Hyrsomallis (2009), only the relaxed impact results were presented. Hyrsomallis (1996, 2009) performed a series of drop tests onto the thighs of 18 volunteers using a steel 2.23 $\mathrm{kg}$ impactor from between $10 \mathrm{~cm}$ and $130 \mathrm{~cm}$, with $>90 \%$ of drops from $50 \mathrm{~cm}$ or less, giving energies up to $21 \mathrm{~J}$. Some of the subjects withdrew after impacts from the higher heights, with more withdrawing after relaxed impacts than tensed impacts. Iwamoto et al. (2015) used a material testing indentor to examine the force deformation relationship of a single subject's upper arm, biceps side, in tensed and relaxed states. They found a marked change in the force displacement curves after $5 \mathrm{~mm}$ of depression, with the tensed condition reaching twice the force of the relaxed condition at $\sim 13 \mathrm{~mm}$. Muggenthaler et al. (2008) used a $0.93 \mathrm{~kg}$ aluminium impactor with impact energies up to $3.64 \mathrm{~J}$ to impact the biceps side of the upper arm in both relaxed and tensed conditions for seven subjects. They found slightly higher decelerations and much greater energy absorption in the relaxed condition, similar to Crisco et al. (1996). However, the use of metal impactors can severely limit the biofidelity of testing for human on human impacts as these are between two nonlinear visco-elastic bodies (Pain et al. 2008; Tsui and Pain 2012). The impact velocities and energies are often greatly reduced in metal impactor and anvil tests from those seen in human on human impacts and a more compliant impactor is therefore preferable (Milburn et al. 2001; Pain et al. 2008).

Despite uncertainty of its exact role, muscle tension has shown an ability to alter human biomechanical response and may have the ability to reduce impact injuries or injury severity. The aim of this study was to examine the effects of muscle tension on human 
impact response in terms of force and energy absorbed and if muscle tension influences the subject's perception of pain. A visco-elastic impactor was used, allowing impacts with greater energies than previously utilised and a more biofidelic human on human type impact. It is hypothesised that being tensed will reduce the severity of the impact as determined by mechanical and subjective measures.

\section{Methods}

Seven male martial artists (age $27 \pm 8 \mathrm{yrs}$, height $1.76 \pm 0.04 \mathrm{~m}$, mass $83.2 \pm 8.0 \mathrm{~kg}$ ) provided informed consent to participate in this study in accordance with the protocol outlined by the Loughborough University Ethical Advisory Committee. Subjects were selected based on their familiarity with, and tolerance to, impacts to the legs, with each subject training for at least four hours per week in martial arts. This ensured that the impact intensity levels were not unfamiliar and that they would be able to distinguish between perceived intensities. Subject numbers were determined from a power analysis for an ANOVA to detect force changes, with a power of 0.8 and $p<0.05$, based on the force results from Crisco et al. (1996) and kept to the minimum subject number needed for ethical reasons. The thigh was chosen as the impact area as it is a favoured target in full contact martial arts with good impacts resulting in the common injury of a dead leg (muscle contusion and numbness) (Bracker 2012). A dead leg is also a common injury in other impact sports such as rugby (Micheli 2010). The thigh is a relatively safe place to test given its large ratio of muscle to bone mass and that the major blood vessels and largest nerves are more posteriorly positioned in the thigh. Thus it is likely that discomfort will be due to muscle compression and if there was to be an unexpected injury it would likely only be a muscle contusion.

Each subject sat in an upright posture with their right thigh resting on the middle of a $0.5 \mathrm{~m}$ wide bench with the right foot planted flat on the ground. Bench height was adjusted until a resting knee angle of $90^{\circ}$ was achieved. The left leg was positioned off the side of the bench, just posterior and inferior to the right leg, to provide an unencumbered view of the impacted thigh. After a short warm-up, consisting of sub-maximal isometric knee extensions, each athlete performed a single isometric maximum voluntary contraction (MVC) for knee extension against an ankle strap placed $2 \mathrm{~cm}$ proximal to the medial 
malleolus, and positioned perpendicular to tibial motion during knee extension/flexion. The strap connect via a steel cable to a bolt screwed into a Kistler 9281b force plate (Winterthur, Switzerland).

In each impact trial, a $3.9 \mathrm{~kg}$ medicine ball was dropped vertically from one of seven different heights, 1.0-1.6 $\mathrm{m}$ in increments of $0.1 \mathrm{~m}$, onto the right thigh. Subjects were instructed to either relax (no muscle contraction) or tense the quadriceps via knee extension ( $\geq 60 \% \mathrm{MVC}$ ) prior to each impact. Muscle activation state was monitored via the force plate readings and visually in real time to check there was no contraction, and visually in the slow motion video between drops. Immediately post-impact, participants were asked to rate their level of discomfort ranging from 0 ('No Pain') to 10 ('Extreme Pain') on a Borg CR10 pain scale. In total each subject was exposed to no more than 20 impacts to obtain a good impact at each height, spread over two sessions with more than 2 days between sessions. This helped to reduce muscle fatigue and bias of their perceived discomfort due to the area becoming overly sensitized from repeated impacts. Drop heights were randomized, but care was taken to ensure that higher energy impacts were not administered in succession to allow for a period of recovery. Subjects were blinded both visually and aurally to the drop heights and the exact time of impact, and time between impacts was at least 120 seconds.

Two F-scan pressure insoles (Tekscan, Boston, MA) were wrapped around the quadriceps of the right thigh for each subject and secured with electrical tape. Sensors were orientated to maximize the measuring area but limit the overlap between sensors, and to prevent creasing or folding of the sensors (Figure 1). In addition to the static calibration specified by the manufacturer sensors were dynamically calibrated using the technique outlined in Pain et al. (2008). Tekscan sensors sampled at $500 \mathrm{~Hz}$ and were used to calculate impact force, contact time and time to peak force. 


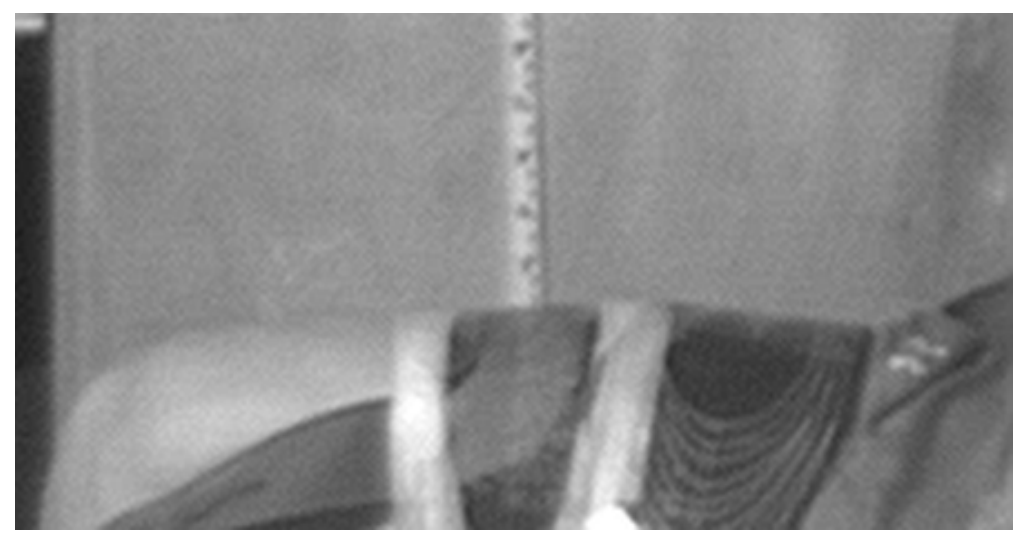

Figure 1. Two F-scan sensors taped over the top and sides of the thigh to minimise overlap and to avoid creasing or folding.

A Phantom V4 High Speed Camera (512 x 512 pixels, Vision Research, Wayne, NJ), sampling at $1000 \mathrm{~Hz}$, recorded each ball-thigh impact in a calibrated area of $0.6 \times 0.6 \mathrm{~m}$. In each trial, the three frames pre- and post-impact were digitised three times at sub pixel resolution using SimiMotion software (Unterschleissheim, Germany). In each frame, the top-, bottom-, left- and right-most points of the ball were digitised. These points were averaged to determine the ball centre and changes in its position were used to calculate inbound and outbound velocity of the impactor in the vertical and anterior-posterior directions. As only one camera was used, any impacts with medial-lateral motions were discarded from analysis and these were identified in a two step process. In order to stop a second impact onto the thigh the medicine ball was caught by a researcher stationed in front of the thigh and if they considered that they caught the ball to their right it was an impact with medial-lateral motion. The second part was all impact videos were visually checked whilst saving them for medial-lateral impacts using the leg and the scale marked in line with the drop of the ball.

To determine the energy lost in deforming the medicine ball for each trial, a function was derived for energy lost at a given impact force for the medicine ball undergoing an impact against a rigid object. To obtain this function, the medicine ball was dropped vertically, between heights of 0.50-1.60 m, onto the force plate whilst recorded by the Phantom video camera, sample rates $2000 \mathrm{~Hz}$ and $1000 \mathrm{~Hz}$ respectively. Energy loss in deforming the

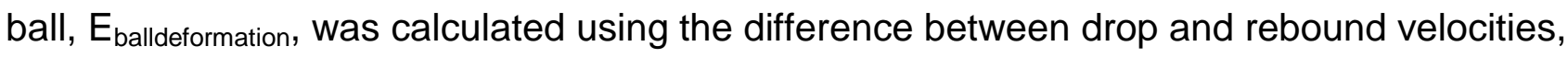
as described in the previous paragraph. This accounted for all energy losses during the ball force plate impact including any minimal frictional losses. Energy lost was plotted 
against impact force and a power function was fitted to predict energy lost at other impact forces (Figure 2).

Energy absorbed by the thigh during impact was then calculated using equation 1 :

$$
E_{\text {absorbed }}=\underbrace{\frac{1}{2} m v_{\text {impact }}^{2}}_{\text {impact energy }}-\underbrace{\frac{1}{2} m v_{\text {rebound }}^{2}}_{\text {rebound energy }}-E_{\text {ball deformation }}
$$

Two way ANOVAs for repeated measures with a Tukey-Kramer pairwise comparison were performed for muscle tension and drop heights using Matlab (The MathWorks Inc., Natick, MA, USA). Contact time and time to peak force were compared for the grouped drop heights between conditions with a paired t-test. Kruskal-Wallis was used for the ordinal discomfort measures. Significance was set at $p<0.05$.

\section{Results}

Mean activation was $65 \%$ of MVC contraction. The energy lost when deforming the medicine ball for a given impact force was well described $\left(R^{2}=0.875\right)$ by the power function:

$$
\text { Energy }=8 \times 10^{-6} \cdot \text { Force }^{1.94}
$$

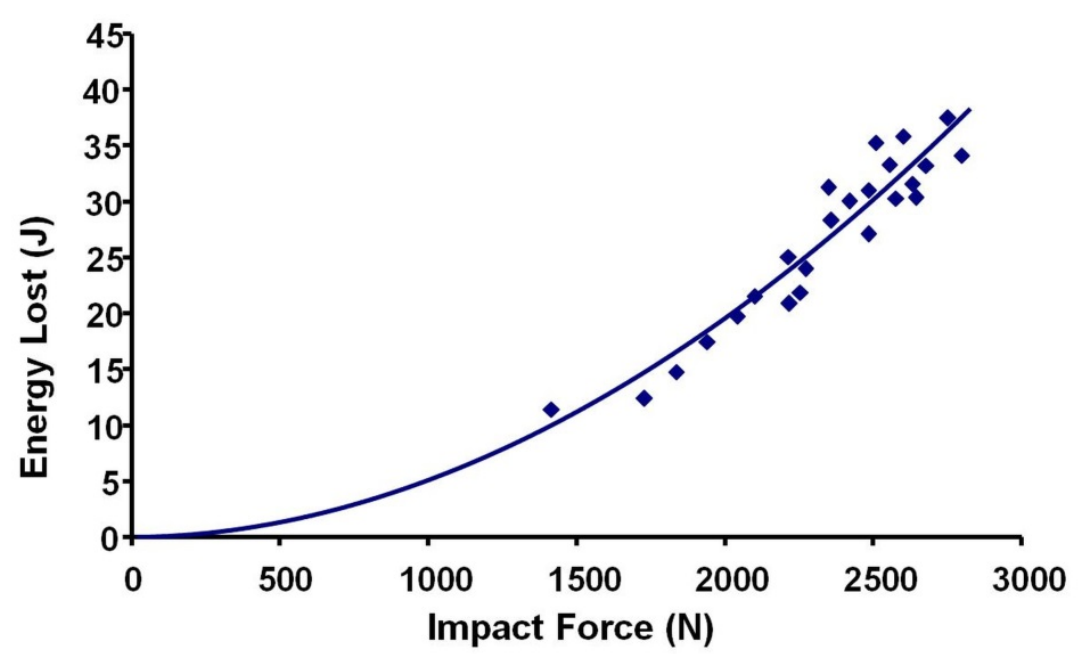

Figure 2. Energy lost deforming the medicine ball plotted against impact force measured by the force plate. This represents the total energy lost by any means by the ball during the impact. 
Impacts onto the thigh of up to $61 \mathrm{~J}$ were achieved with $50-61 \%$ of the impact energy absorbed by the thigh in the tensed condition and $63-70 \%$ in the relaxed condition (Table 1), representing higher energies than previous studies and a more human on human scenario. Tensed peak impact forces were on average $11 \%$ higher than in the relaxed condition, and energy absorbed was $15 \%$ lower in the tensed condition than the relaxed condition (Table 1). Across all heights peak impact force was significantly higher in the tense condition than the relaxed condition $(\mathrm{F}=32.616, \mathrm{p}=0.029)$, and energy absorbed was lower in the tensed condition than the relaxed condition $(F=28.62, p=0.033)$. There was no significant change in impact force with drop height $(F=2.422, p=0.26)$ but there was a significant change in energy absorbed with drop height $(F=5.372, p=0.007)$. Perceived impact intensities for tensed muscle, $1.4 \pm 0.8$, were significantly lower than that for relaxed muscle, $4.2 \pm 1.1$ ( $p 0.016$ ) (Table 2). Tensed impacts had significantly lower time to peak force compared to relaxed impacts $(p=0.003)$ whilst contact times were not significantly different $(p=0.38)$ (Table 2$)$. High-speed video revealed qualitatively greater thigh deformations in the relaxed condition, whilst impactor deformation was greater in the tensed condition (Figure 3), but it was not possible to reliably measure this across subjects with the single camera.

Table 1. Impact force and energy absorption by the thigh for group means and standard deviations per condition, per drop height.

\begin{tabular}{|c|c|c|c|c|}
\hline $\begin{array}{c}\text { Drop Height } \\
\mathbf{( c m})\end{array}$ & $\begin{array}{c}\text { Tensed } \\
\text { Peak Force } \\
(\mathbf{N})\end{array}$ & $\begin{array}{c}\text { Relaxed } \\
\text { Peak Force } \\
\mathbf{( N )}\end{array}$ & $\begin{array}{c}\text { Tensed } \\
\text { Energy Absorbed } \\
\mathbf{( J )}\end{array}$ & $\begin{array}{c}\text { Relaxed } \\
\text { Energy Absorbed } \\
(\mathbf{J})\end{array}$ \\
\hline 100 & $1411 \pm 217$ & $1187 \pm 167$ & $19.0 \pm 5.3$ & $24.3 \pm 5.8$ \\
\hline 110 & $1224 \pm 196$ & $1204 \pm 241$ & $25.8 \pm 4.9$ & $28.0 \pm 4.3$ \\
\hline 120 & $1280 \pm 146$ & $1311 \pm 128$ & $28.6 \pm 4.6$ & $30.3 \pm 4.3$ \\
\hline 130 & $1367 \pm 261$ & $1137 \pm 291$ & $24.5 \pm 6.6$ & $36.2 \pm 6.2$ \\
\hline 140 & $1383 \pm 241$ & $1283 \pm 135$ & $31.6 \pm 7.4$ & $34.1 \pm 3.0$ \\
\hline 150 & $1507 \pm 265$ & $1215 \pm 285$ & $32.2 \pm 8.5$ & $40.1 \pm 8.3$ \\
\hline 160 & $1478 \pm 178$ & $1385 \pm 263$ & $36.8 \pm 3.9$ & $39.4 \pm 3.6$ \\
\hline
\end{tabular}


Table 2. Group mean impact characteristics for each drop height split into muscle condition. TTPF, time to peak force; CT, contact time.

\begin{tabular}{|l|c|c|c|c|c|c|}
\hline \multirow{2}{*}{$\begin{array}{l}\text { (cm) Height } \\
(\mathbf{c m}\end{array}$} & \multicolumn{3}{|c|}{ Tensed } & \multicolumn{3}{c|}{ Relaxed } \\
\cline { 2 - 7 } & TTPF (ms) & CT (ms) & Comfort & TTPF (ms) & CT (ms) & Comfort \\
\hline $\mathbf{1 0 0}$ & $13.4 \pm 1.5$ & $43.4 \pm 6.1$ & $1.0 \pm 0.07$ & $16.0 \pm 2.1$ & $43.8 \pm 5.8$ & $3.9 \pm 0.13$ \\
\hline $\mathbf{1 1 0}$ & $15.1 \pm 2.3$ & $45.7 \pm 5.8$ & $1.0 \pm 0.08$ & $16.5 \pm 1.7$ & $45.5 \pm 7.0$ & $3.8 \pm 0.07$ \\
\hline $\mathbf{1 2 0}$ & $14.4 \pm 2.3$ & $42.2 \pm 4.8$ & $1.0 \pm 0.03$ & $14.3 \pm 2.7$ & $46.0 \pm 6.6$ & $3.8 \pm 0.33$ \\
\hline $\mathbf{1 3 0}$ & $14.4 \pm 2.3$ & $45.6 \pm 4.8$ & $1.3 \pm 0.14$ & $16.0 \pm 2.4$ & $47.8 \pm 8.2$ & $4.1 \pm 0.29$ \\
\hline $\mathbf{1 4 0}$ & $13.8 \pm 2.4$ & $43.6 \pm 4.4$ & $1.4 \pm 0.14$ & $15.3 \pm 1.0$ & $39.3 \pm 6.7$ & $4.1 \pm 0.42$ \\
\hline $\mathbf{1 5 0}$ & $13.0 \pm 3.9$ & $41.7 \pm 4.1$ & $1.5 \pm 0.15$ & $15.2 \pm 1.7$ & $44.0 \pm 9.9$ & $4.8 \pm 0.41$ \\
\hline $\mathbf{1 6 0}$ & $13.4 \pm 2.2$ & $43.1 \pm 5.3$ & $1.7 \pm 0.14$ & $14.9 \pm 1.9$ & $45.7 \pm 8.9$ & $4.9 \pm 0.09$ \\
\hline Mean & $14.0 \pm 2.4$ & $43.7 \pm 4.9$ & $1.4 \pm 0.28$ & $15.6 \pm 2.0$ & $44.6 \pm 7.6$ & $4.2 \pm 0.46$ \\
\hline
\end{tabular}

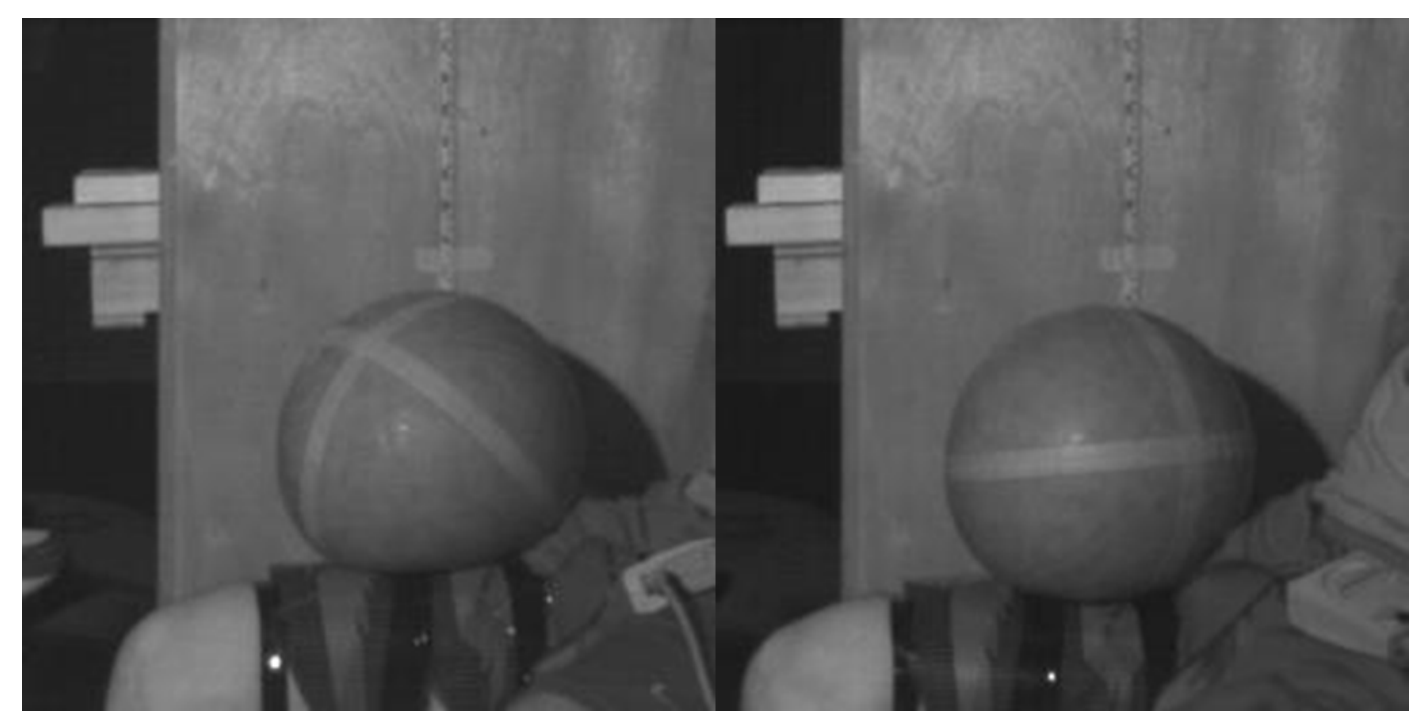

Figure 3. Representative trials from a subject. Left is maximum compression during a tensed impact whilst right is maximum compression during a relaxed impact.

\section{Discussion}

This study aimed to examine the effects of muscle tension on human impact response during a visco-elastic impact in terms of force and energy absorbed and if muscle tension influences the subject's perception of pain. The hypothesis that being tensed will reduce the severity of the impact measures was supported for the subjective perception measures with significantly lower pain index scores when tensed. With regard to significant mechanical measures, across all impacts force was 11\% higher, energy absorption was $15 \%$ lower and time to peak force was $11 \%$ lower when tensed. The results seen here exhibited the same trend as Hrysomallis $(1996,2009)$ which attributed an increased force and decreased time to peak force to a greater hardness or resistance to deformation. The results found in this study are in agreement with those of Hrysomallis $(1996,2009)$ who also observed a lower level of discomfort when tensed. For impacts to a well-muscled area 
higher impact forces, from higher peak decelerations of the impactor, did not cause greater discomfort. If discomfort is a valid proxy for increased injury risk in this experiment then in the tensed condition contusion injuries are less likely when tensed even with the higher peak impact forces.

Crisco et al. (1996) also found that in the tensed condition, for relatively more intense impacts on frogs, less energy was absorbed and less physical damage was done, but they also found that force was decreased. Their explanation was that the tensed muscle stopped the impact being dominated by the bone of the limb, with the stiffer and thickened muscle reducing the compression of the muscle tissue between the impactor and the bone. In this study the impacts were not severe enough that the bone would become a dominant factor and hence the likely reason for this difference in results between studies with regard to force.

Elastic impact theory postulates that higher forces will cause higher internal stresses and subsequently more serious injury, and thus reducing forces during impacts is often a primary goal in injury mitigation practices. However, human impacts are complex as not only are limbs compound structures made of different materials but when muscle changes its structure to contract, it also alters its stress-strain properties. Activated muscle has a much higher stiffness along the line of the fibres than when relaxed, whereas transverse stiffness presents a more complex case and has been seen to decrease, not change much, or increase during electrically stimulated rigor (Sugi and Tsuchiya 1982; Hatta et al. 1988; Tsuchiya et al. 1993).

If muscle injury is primarily caused by the crushing of soft tissue between the impactor and the underlying bone (de Souza and Gottfried; 2013) then there are a number of ways in which tensing muscle can ameliorate this. Increasing the thickness of the muscle under the impact, and increasing the stiffness of the muscle were described as possible mechanisms by Crisco et al. (1996). However, the actual thickness change can be small and impacts are mainly along the transverse axis where stiffness may not have changed, or may even have decreased, and these factors may not be sufficient to account for the large reductions seen in discomfort. Muscle tissue does not grow out from, or sit in a fixed position relative to the underlying bone but is effectively suspended like a thick net of fibres between tendons above the bone. This consideration of the anatomy and morphology of musculo- 
tendon units allows further mechanical methods for reducing compression during impact to be postulated. When relaxed, the net of fibres is slack and resting against the bone and so can easily be crushed up against it with only its inherent transverse stiffness to resist the compression. When tensed the net of fibres would not only have to be compressed, which may be no more difficult than when relaxed if dependent on the transverse stiffness, but depressed down as a whole onto the bone while it is under tension. This means deflecting the fibres and so the resistance to this would be dependent on the tension in the longitudinal direction, plus the geometry of the deflection, as seen in many effective cable tension support systems. An illuminating example, which can be readily felt in the arm of the reader, is shown in Figure 4 which depicts the biceps musculotendon unit in relaxed and contracted conditions. In the relaxed condition the slack tendon, and tissue below it, can be easily pressed down into the humerus and with a forceful application it can become painful quickly. When isometrically tensed, requiring co-contraction of the triceps, the tendon can be felt stiffening and rising up, which alleviates the pain due to tissue compressing against the humerus. Although this easy to experience example is with the tendon the tendon is in series with the muscle belly so has the same force and lines of action. Another factor with this tensioned cable type resistance is that more of the muscle mass than just that directly under the impactor can be involved in the impact and so provides more inertial resistance to compression. This would hold as long as the time is sufficient for propagation of the forces along the fibres. Given the times to peak force found here, $>10 \mathrm{~ms}$, and the speed of sound in muscle being approximately $1540 \mathrm{~m} / \mathrm{s}$ there is time for metres of muscle fibres to become involved.

These mechanisms could also explain that while at each drop height energy absorption was greater in relaxed muscle and correlated positively with discomfort for both muscle conditions, in tensed impacts even when more energy was absorbed by the thigh compared to relaxed impacts discomfort was still much lower. Increasing the effective mass of the impacted body reduces the energy per unit volume that is absorbed, and longitudinally stretching the stiffer activated muscle means more work needs to be done to stretch the tissue a given distance. A further possible non-standard mechanical factor worth considering is that by having the muscle resistance acting along the line of the muscle fibres, elongation by reversible, and less damaging, cross bridge detachment could occur to absorb some of the impact energy. 


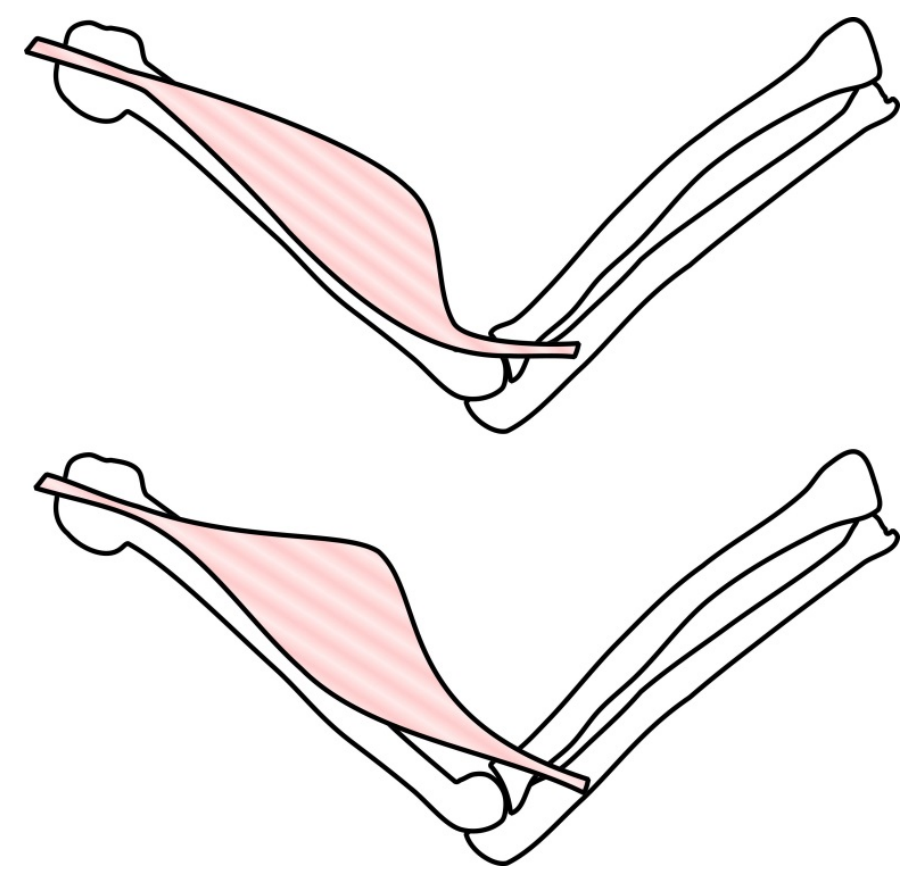

Figure 4. A schematic of the biceps brachii for the same joint angle in relaxed, top, and tensed, bottom, conditions.

One limitation is that in this study, a subjective metric, perceived impact intensity, was used to infer an objective injury outcome (e.g. contusion) on a limited range of subjects. For an individual, especially those with long term experience of impacts, under the same impact conditions the more painful the impact the more likely it is to cause injury. However, injurious impacts can go unnoticed dependent on various psychophysical conditions at the time, such as inattention and the Gated Theory of pain perception (Melzack and Wall 1965). In this study advanced knowledge and equivalent attention was present for all impacts so it is unlikely this would have altered pain perception between conditions. However, Gated Theory proposes that the central nervous system would be busy processing the electrical signals associated with muscle contraction, a larger fibre input, to properly assess the pain stimuli, a small fibre input. As such, the blocked stimuli may have led to lower perceived impact intensities during tensed muscle trials if this was in effect. It should also be noted that the F-scan pressure insoles only measure normal forces and so there is the limitation that not all impact force will have been determined. There could be slight differences in the impact force vectors between the tensed and relaxed conditions with the thigh muscle deforming differently. However, this was difference was considered to be minimal and along with the results not being depended on absolute force values this should not alter the main outcomes of this study. A better dynamic calibration in the future may be to use a 
rigid ellipsoid fixed to the force plate with the F-scan sensors attached to this. Although repeated digitizing and averaging of points was used to get ball velocities and every effort was made to avoid including oblique impacts the use of a 3D system with higher resolution would be advisable in future studies.

Whatever its precise mechanism, it is clear that whether muscle is tensed or not has a significant and meaningful effect on injury risk during human on human type impacts. Unless the activation state of the muscle is known, using force is not a good indicator of pain, and thus likely not a good indicator of injury risk, and that energy absorption may be a more appropriate parameter to consider for these intensities of impacts onto human musculature. Given the large difference in perceived discomfort and the mechanical differences in a tensed condition from a relaxed condition, muscle tension state needs consideration for the development of more biofidelic impact models, both physical models and computer simulations. 


\section{Acknowledgments}

This work was in part funded by an EPSRC PhD studentship.

\section{Disclosure of Conflict of interest}

There are no conflicts of interest. 


\section{References}

Backaitis, S.H. and St-Laurent, A. 1986. Chest deflection characteristics of volunteers and Hybrid III dummies. 30th Stapp Car Crash Conference. SAE Paper 861884, 157-166.

Backer, M.D. 2012. The 5-Minute Sports Medicine Consult, $2^{\text {nd }}$ edition. Lippincott Williams \& Wilkins. ISBN-13: 978-1605476681.

Bauer, J.A., Thomas, T.S., Cauraugh, J.H., Kaminski, T.W., and Hass. C.J. 2001. Impact forces and neck muscle activity in heading by collegiate female soccer players. Journal of Sports Sciences, 19:3, 171-179.

Brolin, K., Halldin, P. and Leijonhufvud, I. 2005. The effect of muscle activation on neck response. Traffic Injury Prevention, 6:1, 67-76.

Cazzola, D., Stone, B., Holsgrove, T.P., Trewartha, G. \& Preatoni, E. 2015. Spinal muscle activity in simulated rugby union scrummaging is affected by different engagement conditions. Scandinavian Journal of Medicine \& Science in Sports, 26, 432-40.

Crisco, J.J., Hentel, K.D., Hackson, W.O., Goehner, K., and Joki, P. 1996. Maximal contraction lessens impact response in a muscle contusion model. Journal of Biomechanics, 29(10), 1291-1296.

Eckner, J.T., Youkeun O.S., Joshi, M.S., Richardson, J.K., and Ashton-Miller, J. 2014. Effect of neck muscle strength and anticipatory cervical muscle activation on the kinematic response of the head to impulsive loads. The American Journal of Sports Medicine, 42, 566-576.

Hatta, I., Sugi, H., and Tamura, Y. 1988. Stiffness changes in frog skeletal muscle during contraction recorded using ultrasonic waves. Journal of Physiology, 403, 193-209.

Hrysomallis, C. 1996. Anthropomorphic thigh for impact assessment. PhD thesis, Victoria University of Technology. http://vuir.vu.edu.au/id/eprint/15607 
Hrysomallis, C. 2009. Surrogate thigh model for assessing impact force attenuation of protective pads. Journal of Science and Medicine in Sport, 12: 35-41.

Iwamoto, M., Nakahira, Y. and Sugiyama, T. 2015. Investigation of pre-impact bracing effects for injury outcome using an active human FE model with 3D geometry of muscles. Proceedings of the 22nd International Technical Conference on the Enhanced Safety of Vehicles (ESV), published by National Highway Traffic Safety Administration

Kemper, A.R., Beeman, S.M., Madigan, M.L., and Duma, S.M. 2014. Human Occupants in Low-Speed Frontal Sled Tests: Effects of Pre-Impact Bracing on Chest Compression, Reaction Forces, and Subject Acceleration. Traffic Injury Prevention, 15, S141-S150.

Kent R, Bass C, Woods W, Sherwood C, Madeley N, Salzar R, and Kitagawa Y. 2003. Muscle tetanus and loading condition effects on the elastic and viscous characteristics of the thorax. Traffic Injury Prevention, 4(4):297-314

Kent R.W., Bass C.R., Woods W.A., Salzar R.S., sang-Huyn Lee and Melvin, J. 2006. The role of muscle tensing on the force-deflection response of the thorax and a reassessment of frontal impact thoracic biofidelity corridors. Proceedings of the Institution of Mechanical Engineers Part D: Journal of Automobile Engineering, 220, 853-868.

Lobdell, T.E., Kroell, C. K., Schneider, D. C., Hering, W. E. and Nahum, A. M. 1973. Impact response of the human thorax. In: Human Impact Response: Measurement and Stimulation (Eds W. F. King and H. J. Mertz), pp 201-245. (Plenum Press, New York)

Melzack R., and Wall P.D. 1965. Pain mechanisms: a new theory. Science, 150 (3699):971-979.

Micheli, L.J. 2010. Encyclopedia of Sports Medicine volume 1, $1^{\text {st }}$ edition. Sage publishing ISBN-13: 978-1412961158.

Milburn PD, Wilson BD, Chalmers DJ. 2001. Evaluation of body protection clothing in rugby union. Dunedin, New Zealand: University of Otago. 
Muggenthaler, H., Von Merten, K., Peldschus, S., Holley, S., Adamee, J., Praxl, N., and Graw, M. 2008. Experimental tests for the validation of active numerical human models. Forensic Science International, 177, 184-191.

Pain, M.T.G. and Challis, J.H. 2001. The role of the heel pad and shank soft tissue during impacts: A further resolution of a paradox. Journal of Biomechanics, 34(3), 327-333.

Pain, M.T.G. and Challis, J.H. 2002. Soft tissue motion during impacts: their potential contribution to energy dissipation. Journal of Applied Biomechanics, 18 (3), 231-242.

Pain, M.T.G. and Challis, J.H. 2004. Wobbling mass influence on impact ground reaction forces: a simulation model sensitivity analysis. Journal of Applied Biomechanics, 20 (3), 309-316.

Pain, M.T.G. and Challis, J.H. 2006. The influence of soft tissue movement on ground reaction forces, joint torques and joint reaction forces in drop landings. Journal of Biomechanics, 39 (1), 119-124.

Pain, M.T.G., Tsui, F., and Cove. S. 2008. In vivo determination of the effect of shoulder pads on tackling forces in rugby. Journal of Sports Sciences, 26 (8), 75-82.

Patrick, L.M. 1981. Impact Force-Deflection of the Human Thorax. $25^{\text {th }}$ Stapp Car Crash Conference. SAE Paper 811014, 471-495.

Payne, T., Mitchell, S., Halkon, B., Bibb, R., and Waters, M. 2016. Development of a synthetic human thigh impact surrogate for sports personal protective equipment testing. Proceedings of the Institution of Mechanical Engineers, Part P: Journal of Sports Engineering and Technology, 230, 5-16.

Seminati, E., Cazzola, D., Preatoni, E. and Trewartha, G. 2016. Specific tackling situations affect the biomechanical demands experienced by rugby union players. Sports Biomechanics, 16, 58-75. 
de Souza, J., and Gottfried, C. 2013. Muscle injury: Review of experimental models. Journal of Electromyography and Kinesiology, 23, 1253-1260.

Stalnaker, R.L., McElhaney, J.H., Roberts, V.L., and Trollope, M.L. 1973. Human torso response to blunt trauma. In: Human Impact Response: Measurement and Stimulation (Eds King, W.F., and Mertz, H.J.), pp 181-199. Plenum Press, New York.

Sugi, H. and Tsuchiya, T. 1982. Changes in muscle stiffness during contraction recorded using ultrasonic waves. Nature, 299, 631-633.

Tsuchiya, T., Iwamoto, H., Tamura, Y., and Sugi, H. 1993. Measurement of transverse stiffness change during contraction in frog skeletal muscle by scanning laser acoustic microscope. In: Mechanism of Myofilament Sliding in Muscle Contraction (Eds Sugi, H., and Pollack, G.H) pp 715-724, Springer, New York.

Tsui, F., and Pain, M.T.G. 2012. Utilising human performance criteria and computer simulation to design a martial arts kicking robot with increased biofidelity. Proceedings of the Institution of Mechanical Engineers, Part $P$, Journal of Sports Engineering and Technology, 226, 244-252.

Whiting and Zernicke, 2008 Biomechanics of Musculoskeletal Injury $2^{\text {nd }}$ Edition Human Kinetics ISBN-13: 9780736054423. 